\title{
Prevalence of Postpartum Depression and Associated Factors among Postnatal Women Attending At Hiwot Fana Specialized University Hospital, Harar, East Ethiopia, $2015 / 2016$
}

\author{
Abayneh Shewangzaw ${ }^{1 a}$, Bilisuma Tadesse ${ }^{1}$, Tiba Ashani $^{1}$, Tadesse Misgana ${ }^{1}$ and Sisay Shewasinad ${ }^{* 2}$ \\ ${ }^{1 a}$ Lecturer at Debre Birhan University, Ethiopia \\ ${ }^{1}$ Lecturer at Haramaya University, Ethiopia \\ ${ }^{2}$ Lecturer at Debre Birhan University, Ethiopia
}

Received: January 02, 2018; Published: January 19, 2018

*Corresponding author: Sisay Shewasinad, Lecturer at Debre Birhan University, Ethiopia

Abstract

Background: Postpartum depression is a common occurrence which is often undiagnosed when symptoms are not severe and may progress into severe or chronic state if unrecognized and untreated. Being the most frequent form of mental illness in the postpartum period, it can begin as early as two weeks after delivery. It is also the most common complication of childbearing and as such represents a considerable public health problem affecting women and their families.

Objective: To assess the prevalence of postpartum Depression and associated factors among postnatal women who are attending at Hiwot Fana Specialized University Hospital, Eastern Ethiopia, 2016.

Methods: The study was conducted by using institutional based cross-sectional study design and non probability convenience sampling technique, until the required sample size of 122 was attained. The data was collected by using a structured, pre designed questionnaire from February 22/02/2016-March 22/03/2016. The data was analyzed manually and presented by using frequency table and graphs.

Results: A total of 122 postnatal mothers were involved into this study and all of them were analyzed. This study found a prevalence of PPD one week after delivery at HFSUH was $13.11 \%$. Recent pregnancy was reported as unwanted by $2.46 \%$ and partner's support was perceived as inadequate by $19 \%$ of the respondents and Caesarian section was $38.52 \%$. Almost all, $95.90 \%$ exclusively breast fed their infants and minor illnesses had occurred to $13.11 \%$ of the infants. Premature baby $5.74 \%$, poor satisfactions with medical care $22.13 \%$, family history of mental illness 3.28\% were strongly associated with PPD. The other factors such as neonate illness, residence, desired new born sex, hypertension, and hyper emesis had also their own significant association. Educational status, number of birth, age, place of delivery and sex of new born had no significant association with PPD.

Conclusion: This study found a prevalence of PPD among women delivering at HFSUH, one week after delivery was $13.11 \%$ which is a significant high value and compared well with other studies. The findings in this study may form the bases for the need of routine screening of PPD in the post natal care especially those mothers with unplanned pregnancy, premature baby, poor support systems, poor satisfaction with medical care, family history of mental illness, and stressful life events which were highly associated with PPD. This would help prevent PPD at all levels hence a healthy mother.

Recommendation: Psychiatry staff of HFSUH should collaborate the services given for psychiatric cases and other gynecologic and obstetrics as well as general medical conditions. Routine screening for mental illness just like other reproductive problems for mothers attending hospital during delivery and after delivery is necessary. Finally, ministry of health should design policy that interactively provides mental illness of mother and their reproductive problems.

Ethical consideration: The study was conducted after ethical clearance had been given from Haramaya University College of Health and Medical Science. Ethical clearance letter was submitted to Hiwot Fana Specialized University Hospital and management body permitted to conduct research.

\section{Introduction}

\section{Background}

Postpartum depression also known as postnatal depression is a non psychotic depressive disorder of variable severity and it can begin as early as two weeks after delivery and can persist indefinitely if untreated. Most of the time, it occurs within the first three month after delivery. The illness can cause distress and impair a mother's ability to carry out her normal tasks, care for herself and care of her 
baby. It is a clinical depression with symptoms that can include a feeling of fatigue, social withdrawal, sadness, changes in sleeping and eating patterns, and guilt (including related to ability to care for the infant), crying, loneliness and low self esteem lasting longer than two weeks or beginning two weeks or more after delivery $[1,2]$. The term "Post $\neg$ partum Depression" encompasses several mood disorders that follow childbirth. Important developments in the study of PPD include its association with symptoms of anxiety and bipolar disorders in addition to those of depression [2].

Becoming a mother can be difficult this is due to a major psychological shift from viewing oneself as a woman who is pregnant to viewing oneself as a new mother. This major emotional shift may create problems. Following childbirth, seesawing emotions and heightened emotional responses may occur [3]. The biological mechanism of PPD is believed to coincide with that of major depressive disorder. Depression in general is a disease of neuronal circuit integrity, which has been shown in studies by a reduction in brain volume of individuals diagnosed with major depressive disorder. Interestingly, the amount of volume loss correlates directly with the number of years of ill $\neg$ ness. Stress and depression act to reduce numerous brain pro $\neg$ teins that promote neuronal growth and synapse formation, and antidepressant medications have been shown to increase these and other protective proteins, thereby reversing the mechanism of depression.

These underlying neurobiological changes result from developmental interactions between genetic susceptibility and environmental factors (i.e., the psychosocialstresses ac $\neg$ companying motherhood) rather than a simple "chemical im $\neg$ balance," as previously believed. Specifically, the neurobiolog $\neg$ ical effects of rapid postpartum hormone withdrawal predispose women with established risk factors to PPD. An interesting distinction that makes PPD unique from other depressive disorders is that it is marked by a prominent anxi-ety component. This may be why so many cases of PPD are missed, as many clinicians use the Patient Health Question $\neg$ naire which covers depressed mood and dysphoria, but not anxiety-as their primary screening technique. The stress of caring for a newborn or even the circumstances surrounding labor and delivery may precipitate the first symp ᄀtoms of PPD [4].

Multiple risk factors for postpartum depression have been suggested as no single cause has been identified. Personal vulnerability, personal traits and social factors such as unplanned pregnancy occupational instability, single parenthood and marital discord have been cited. The effects of postnatal depression on the mother, her marital relationship, and her children make it an important condition to diagnose, treat and prevent. The mother unable to provide care to her infant as manifested by decreased adherence to regular check up well baby visits and increased frequency health care provider's visits due to infant problems. Lastly depressed mothers have lower rates of gratification and enjoyment in their mothering role compared with non-depressed mothers. The patterns of symptoms in women with postpartum depression are similar to those in women who have depression unrelated to childbirth apart from the fact that the content may focus on the delivery or baby. Evidence from epidemiological and clinical studies suggests that mood disturbances following childbirth are not significantly different from affective illnesses that occur in women at other times $[5,6]$.

\section{Statement of the problem}

Postnatal depression (PND) is a global public health issue. It is the most common complication of childbearing and as such represents a considerable public health problem affecting women and their families. The effects of postnatal depression on the mother, her marital relationship, and her children make it an important condition to diagnose, treat and prevent [2]. Postpartum Depression (PPD) encompasses several mood dis $\neg$ orders that follow childbirth. It affects $10-15 \%$ of new mothers, but many cases of PPD remain undiagnosed. Thus, prevalence rates in the developing world range from being equal to almost double that of developed countries. Risk factors identified in these studies include previous psychiatric problems, life events in the previous year, poor marital relationship and economic deprivation. Female infant gender was found to be an important determinant of postnatal depression in India but not in South Africa.

These studies found that postnatal depression was associated with high degrees of chronicity, disability and disturbances of mother infant relationship [7]. Postpartum common mental disorders such as depression and anxiety are increasingly recognized for their burden in low resource countries such as Ethiopia. However; the magnitude of postpartum depression in Ethiopia is not well established so identifying magnitude of postpartum depression and associated factors in our country is essential to minimize mental illness that is related to mothers who give birth. Estimates for depression during and after pregnancy have range from $9 \%$ to $20 \%$, and for postpartum common mental disorder, the estimates have been as high as $33 \%$, even if these problems are there, there is no good awareness and satisfactory intervention especially for those who live in remote area from the health center [8].

Multiple risk factors for postpartum depression have been suggested as no single cause has been identified. Personal vulnerability, personal traits and social factors such as unplanned pregnancy, occupational instability, single parenthood and marital discord have been cited. Screening for postpartum depression would improve the ability to recognize these disorders and hence necessitate enhanced care that ensures appropriate clinical outcomes [6]. Untreated postpartum depression can have adverse long term effects. For the mother, the episode can be the precursor of chronic or recurrent depression. For her children, a mother's ongoing depression can contribute to emotional, behavioral, cognitive and interpersonal problems in later life. If postpartum depression is to be prevented by clinical or public health intervention, its risk factors need to be reliably identified, however, numerous studies have produced incomplete consensus on these [5].

This research is relevant because the prevalence of PPD and its associated factors are not well known as well as there is no proper intervention. Determining the prevalence of PPD is critical 
to manage and prevent further complication. It will also help to identify its impacts on mother and child. The purpose of this study is to evaluate the prevalence of PPD and associated factors; it is expected to sensitize the health care professionals and policy makers on the importance of maternal mental health and the need for routine screening for postpartum depression by disseminating/ reporting the result of the research at Hiwot Fana Specialized University Hospital by the year 2015/16.

\section{Significance of the study}

In Ethiopia there are no published researches (up to our reading) on PPD and its associated factors, due to this our study plays an important role to determine and solve the problem by disseminating the result to concerned bodies. This study provides an evidence base from which further studies can be done and compared, not just at this hospital only, but from other hospitals in Ethiopia. It serves as initial to do further research and a pioneering study for our junior students and other investigators toward future studies among related subjects. It also expands our knowledge about the various aspects of PPD among Harar women in order to focus on coming researches. Significance to public health and maternal health practice: This study is expected to unveil and draw the attention of health care practitioners to many ignored aspects of PPD and its associated factors, in order to give them more focus towards the integration of PPD screening during the care of pregnant and postpartum women.

Significant to health care decision makers: The study is expected to urge health care decision makers to consider this important topic - PPD in the planning and delivering of health care services.

\section{Study Objectives}

\section{General objective}

a. To assess the prevalence of postpartum Depression and associated factors among postnatal women attending at Hiwot Fana Specialized University Hospital, Harar, Eastern Ethiopia in 2015/16.

\section{Specific Objectives}

a. To determine the prevalence of PPD among postnatal women attending at Hiwot Fana Specialized University Hospital, Harar, Eastern Ethiopia in 2015/16.

b. To identify the factors that associated with PPD among postnatal women attending at Hiwot Fana Specialized University Hospital, Harar, Eastern Ethiopia in 2015/16.

\section{Methods}

\section{Study Area}

This study was conducted in Harar, the capital of the Harari national state. Harar is the capital city of Harari Regional state is located in Eastern part of Ethiopia which is $525 \mathrm{Km}$ from Addis Ababa with a total area of $17.20 \mathrm{Km}^{2}$. According to the regional profile $90 \%$ of the region is estimated to be "woinedega" (Between 1000-1500m) and situated at 900, 230 Altitude and 420, 240 longitude and with elevation of 1600 feet above the sea level.
According to the 2007 census, the regional state of Harari has a total population of 183,415 . The region has $77.6 \%$ health coverage, two Zonal Hospital MAH and HFSU, one regional public health laboratory and research center and one nursing school. Moreover, there are two other governmental hospital army Hospital and Public Hospital [9]. Among Hospitals HFSUH, Jegola Hospital and Army Hospital provide psychiatry service. Jegola Hospital has 1 0PD and 2 staffs (1BSC, 1 advanced Diploma psychiatric Nurses) and in Army Hospital 1 OPD (1Psychiatry nurse). HFSUH has 7 beds, 2 OPDs, 10 staffs (8BSc psychiatry Nurses, 2 Diploma Psychiatry Nurses, But currently no psychiatrist), and also there are 2 gynecology ward and 1 OPD, 14 obstetrics ward and 6 pediatric [10].

\section{Study design and period}

Study design: Institutional based cross sectional study design was used to determine prevalence of postpartum depression and associated factors among postnatal women attending at Hiwot Fana Specialized University Hospital.

Study period: The study was conducted from February 22/02/2016-March 22/03/2016.

\section{Population}

Source population: All postnatal mothers who attended at Hiwot Fana Specialized University Hospital.

Study population: A postnatal mother who attended at Hiwot Fana Specialized University Hospital during the data collection period and who's the data was taken.

\section{Sample size determination and sampling technique}

Sample size determination: The formula that we have used to calculate sample size in the study was:

$n o=\frac{\left(z \frac{\alpha}{2}\right)^{2} p q}{d^{2}}$

Where $d=$ margin of error $=5 \%$ in case of our study

$\alpha=$ level of confidence (95\%- 1.96)

$\mathrm{P}=$ Prevalence of point under consideration that taken as $50 \%$ because there is no known prevalence.

By this no=sample size

$$
n o=\frac{(1.96)^{2}(0.5 \times 0.5)}{(0.05)^{2}}
$$

no $=384$

We add Non respondent rate $=10 \%$, from this no $=423$

We Use reduction formula because our total population is less than 10,000 (the average of total post natal

women in the last year on February and this year on January is 170).

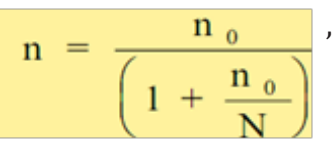




$$
n f=\frac{(423)}{1+423 / 170}=121.2647 \approx 122
$$

Sampling technique: Data was taken from patients who are present at a time of data collection, because of this, non probability convenience sampling technique was applied to select study unit among PPD patients.

\section{Inclusion and exclusion criteria}

\section{Inclusion criteria:}

a. Post natal women who are attending at Hiwot Fana Specialized University Hospital.

b. Age 15-47 or reproductive age group.

c. Ability and acceptance to consent to participate in the study.

\subsubsection{Exclusion criteria}

d. Patients, who cannot able to communicate,.

e. Patients, who have depression that persist beyond 1 year after giving birth.

f. Patients who are not volunteer to participate in the study.

\section{Study variables}

\section{Dependent variable}

Postpartum depression

\section{Independent variable}

Socio demographic factors:
a. Age
b. Occupation
c. Residence
d. Income
e. Marital status
f. Educational status
g. Pregnancy and birth related factors:
h. obstetric history
i. complication during delivery
j. $\quad$ place and type of delivery
k. whether mother wanted pregnancy to occur
l. medical problem or chronic diseases
m. New born related factors:
n. desired gender of new born,
o. whether the new born has any diseases
p. whether the new born is delivered before 9-month
q. whether he/she is fed by breast or formula or both
r. Maternal and family related factors:
s. relationship with her husband and her family members
t. support and help provided by her husband
u. Psychosocial and psychological factors:
v. personal and family history of mental illness
w. history of depression during the last pregnancy
x. $\quad$ stressful life event like loss of loved one

\section{Data collection procedure}

Data collection: Data was collected by using both interview guided structured questionnaire and standard questionnaires by three Data collectors, every data collector interviewed the participants to the questionnaire voluntarily after informed consent has obtained by convincing the patient, their information was confidential.

Data collection instrument: The structured and standard questionnaire which contains the following:

a. Socio-demographic history(age, sex, marital status, education, occupation, residence, income)

b. Pregnancy and birth related factors (obstetric history, complication, place and type of delivery, whether mother wanted pregnancy to occur, medical problem or chronic diseases).

c. New born related factors (desired gender of new born, whether the new born has any diseases, whether the new born is delivered before 9-month, whether he/she is fed by breast or formula or both)

d. Maternal and family related factors(relationship with her husband and her family members, support and help provided by her husband)

e. Psychosocial and psychological factors(personal and family history of mental illness, history of depression during the last pregnancy, stressful life event)

f. Edinburg post natal depression scale

All the above tools were used to determine the prevalence and associated risk factors of postpartum depression among post natal women attending at Hiwot Fana Specialized University Hospital.

\section{Data quality control}

The quality of data was kept by preparing each and every question related to our specific objectives and we incorporated comments obtained in Amharic language and we conducted it. We were also tried to improve our data by sharing information from advisor and using standard data collection tools. Clear discussion was done by group members about the purpose and procedures of the study. The group members were decided to peruse non respondents by explaining the objective of study clearly. The collected data was checked out for the completeness, accuracy and clarity by principal investigator. This quality checking was done 
daily after data collection and amendment was made before the next data collection measure.

\section{Data processing and Analyzing}

Data processing: The collected data was processed manually and using scientific calculators and the raw data was processed by using tallying sheet, filling mater sheet, editing, cleaning and checking for completion.

Data Analyzing: The data was analyzed by using table, figure, frequency, percentages, and cross tabulation. Finally the finding of the study was summarized, presented, discussed based on the nature of questions. The association of factors was analyzed by calculating odd ratio and chi- square.

\section{Ethical Consideration}

The study was conducted after ethical clearance is given from Haramaya University College of Health and Medical Science. Ethical clearance letter was submitted to Hiwot Fana Specialized University Hospital and management body was permitted to conduct research. The objectives of study were clarified to Hiwot Fana Specialized University Hospital and informed consent was agreed as well as notified to patients and their information was not observed by other body that was for the sake of research. A patients verbally counseled regarding their ability to chose whether or not they wanted to participate in the study and the fact that they would not be victimized should they chose not to participated.

\section{Results}

A total of 122 mothers were interviewed, all were eligible for analysis (with 100\% response rate). Results were presented in tables, percentages, and graphs followed by narration as shown below.

\section{Section one: Demographic information:}

Table 1: Socio-demographic characteristics of the participants in Harar town, Hiwot Fana Specialized University Hospital from February 1-30, 2016

\begin{tabular}{|c|c|c|c|}
\hline Variables & & Frequency & $\%$ \\
\hline \multirow{7}{*}{ 1. Age } & a. $15-19$ & 6 & 4.92 \\
\hline & b. $20-24$ & 58 & 47.54 \\
\hline & c.25-29 & 35 & 28.69 \\
\hline & d. $30-34$ & 16 & 13.12 \\
\hline & E.35-39 & 5 & 4.10 \\
\hline & $\mathrm{F} . \geq 40$ & 2 & 1.64 \\
\hline & Total & 122 & 100 \\
\hline \multirow{5}{*}{ 2. Ethinicty } & a. Amhara & 16 & 13.11 \\
\hline & b. Oromo & 79 & 64.75 \\
\hline & c. Harari & 13 & 10.66 \\
\hline & d. others & 14 & 11.48 \\
\hline & Total & 122 & 100 \\
\hline \multirow{5}{*}{ 3. Marital Status } & a. married & 121 & 99.18 \\
\hline & b.single & 1 & 0.82 \\
\hline & c.divorce & - & - \\
\hline & d. widowed & - & - \\
\hline & E.Total & 122 & 100 \\
\hline \multirow{3}{*}{ 4. Residence } & a. urban & 69 & 56.56 \\
\hline & b. rural & 53 & 43.44 \\
\hline & Total & 122 & 100 \\
\hline \multirow{6}{*}{ 5. Educational Status } & a. unable to read and write & 62 & 50.82 \\
\hline & b. only reading and writing & - & - \\
\hline & c. Elementary school & 27 & 22.13 \\
\hline & d. High school and preparatory & 20 & 16.39 \\
\hline & e. College graduate & 13 & 10.66 \\
\hline & Total & 122 & 100 \\
\hline \multirow{4}{*}{ 6. Family Monthly Income } & $<750$ & 66 & 54.10 \\
\hline & $750-1200$ & 44 & 36.07 \\
\hline & $<1200$ & 12 & 9.84 \\
\hline & Total & 122 & 100 \\
\hline
\end{tabular}




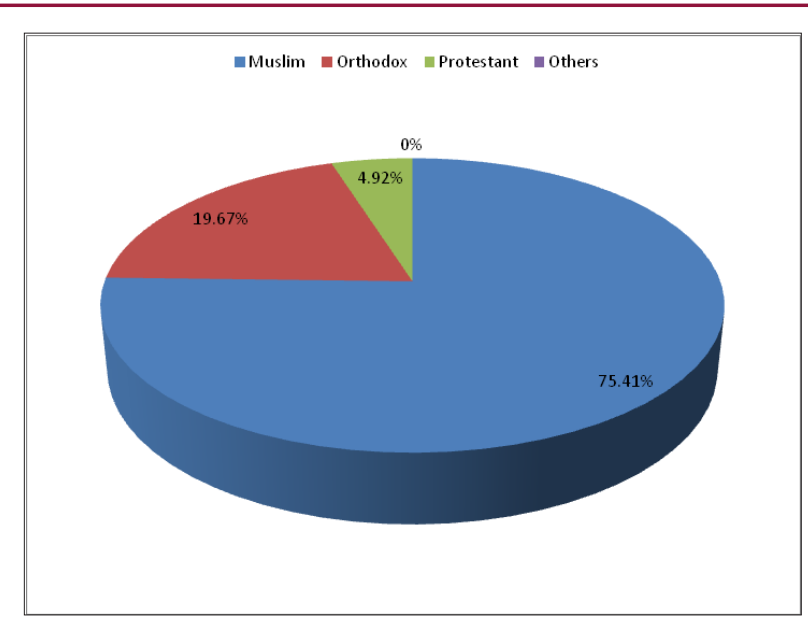

Figure 1: Sociodemographic characteristics (religion) of the participants in Harar town, Hiwot Fana Specialized University Hospital from February 1-30, 2016. Out of the total participants $51.64 \%$ were not employed, $8.20 \%$ government employed, $1.64 \%$ self employed, $25.41 \%$ farmer, $0.82 \%$ student, and $12.26 \%$ merchant.

As Table 1 show below $47.54 \%$ were aged 20-24 years, $28.69 \%$ were aged $25-29,0.82 \%$ was single and the rest were married,
$50.82 \%$ were unable to read and write, $22.13 \%$ had schooled up to primary level and $64.75 \%$ were Oromo. $56.56 \%$ of participants were lived in urban and the rest were in rural. $54.10 \%$ of the participants had $<750$ birr per month per individual of the family. Muslims were the majority of them which accounts $75.41 \%$, followed by Orthodox $19.67 \%$, and protestant $4.92 \%$ (Figures 1 \& 2). Out of the total participants $51.64 \%$ were not employed, $8.20 \%$ government employed, $1.64 \%$ self employed, $25.41 \%$ farmer, $0.82 \%$ student, and $12.26 \%$ merchant.

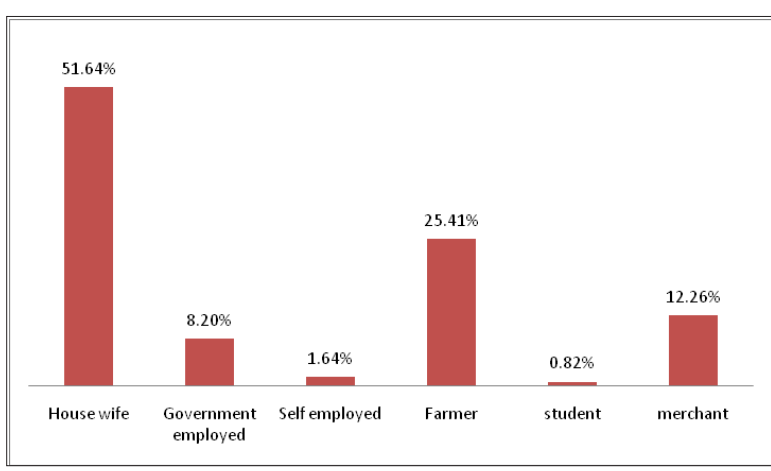

Figure 2: Sociodemographic characteristics (occupational status) of the participants in Harar town, Hiwot Fana Specialized University Hospital from February 1-30, 2016.

\section{Section two: Pregnancy and Birth related factors:}

Table 2: Pregnancy and Birth related factors of the participants in Harar town, Hiwot Fana Specialized University Hospital from February 1-30, 2016.

\begin{tabular}{|c|c|c|c|c|}
\hline \multicolumn{2}{|c|}{ Variable } & & Frequency & $\%$ \\
\hline \multirow{15}{*}{ Pregnancy and birth history } & \multirow{3}{*}{$\begin{array}{l}\text { Number of } \\
\text { Pregnancy }\end{array}$} & a. Primi gravid & 29 & 23.77 \\
\hline & & b. Multi gravid & 93 & 76.23 \\
\hline & & Total & 122 & 100 \\
\hline & \multirow{3}{*}{ Number of births } & a. Primi parity & 37 & 30.83 \\
\hline & & b. Multiple parity & 83 & 69.17 \\
\hline & & Total & 120 & 100 \\
\hline & \multirow{3}{*}{$\begin{array}{l}\text { Number of miscarriage and } \\
\text { stillbirths }\end{array}$} & Yes & 35 & 28.69 \\
\hline & & No & 87 & 71.31 \\
\hline & & Total & 122 & 100 \\
\hline & \multirow{3}{*}{$\begin{array}{l}\text { Number of miscarriage and } \\
\text { stillbirths }\end{array}$} & a. 1 & 20 & 57.14 \\
\hline & & b. $\geq 2$ & 15 & 42.86 \\
\hline & & Total & 35 & 100 \\
\hline & \multirow{3}{*}{ Number of live children } & a. 1 & 35 & 29.66 \\
\hline & & b. $\geq 2$ & 83 & 70.34 \\
\hline & & Total & 118 & 100 \\
\hline \multirow{3}{*}{\multicolumn{2}{|c|}{$\begin{array}{l}\text { Pregnancy related problems occurred during the last } \\
\text { pregnancy }\end{array}$}} & a. Yes & 9 & 7.38 \\
\hline & & b. No & 113 & 92.62 \\
\hline & & Total & 122 & 100 \\
\hline \multirow{4}{*}{\multicolumn{2}{|c|}{ Place of birth }} & a. Home & 1 & 0.82 \\
\hline & & b. Health institution & 121 & 99.18 \\
\hline & & c.Others & - & - \\
\hline & & Total & 122 & 100 \\
\hline
\end{tabular}




\begin{tabular}{|c|c|c|c|}
\hline \multirow{3}{*}{ Route of last delivery } & a. Vaginal delivery & 75 & 61.48 \\
\hline & b. Caesarean section & 47 & 38.52 \\
\hline & Total & 122 & 100 \\
\hline \multirow{3}{*}{ Use of vacuum } & a. yes & 3 & 2.46 \\
\hline & b. no & 119 & 97.54 \\
\hline & Total & 122 & 100 \\
\hline \multirow{3}{*}{ Episiotomy } & a. yes & 3 & 2.46 \\
\hline & b. no & 119 & 97.54 \\
\hline & Total & 122 & 100 \\
\hline \multirow{3}{*}{ Wish to have the last pregnancy } & a. yes & 119 & 97.54 \\
\hline & b. no & 3 & 2.46 \\
\hline & Total & 122 & 100 \\
\hline \multirow{3}{*}{ Plan with husband to the last pregnancy } & a. yes & 119 & 97.54 \\
\hline & b. no & 3 & 2.46 \\
\hline & Total & 122 & 100 \\
\hline \multirow{5}{*}{ Medical care during birth } & a. Poor & 3 & 2.46 \\
\hline & b. Satisfactory & 24 & 19.67 \\
\hline & c. Good & 61 & 50 \\
\hline & d. very good & 34 & 27.87 \\
\hline & Total & 122 & 100 \\
\hline
\end{tabular}

Table 3: marital and Family relationship satisfactions of the participants in Harar town, Hiwot Fana Specialized University Hospital from February 1-30, 2016

\begin{tabular}{|c|c|c|c|}
\hline Variable & Categories & Frequency & $\%$ \\
\hline \multirow{6}{*}{ Relationship with husband } & a. Very Poor & 1 & 0.83 \\
\hline & b. Poor & 2 & 1.65 \\
\hline & c. Satisfactory & 18 & 14.87 \\
\hline & d. Good & 65 & 53.73 \\
\hline & e. Very good & 35 & 28.92 \\
\hline & Total & 121 & 100 \\
\hline \multirow{6}{*}{ Help and support provided by husband } & a. Very Poor & 1 & 0.83 \\
\hline & b. Poor & 6 & 4.96 \\
\hline & c. Satisfactory & 16 & 13.22 \\
\hline & d. Good & 63 & 52.07 \\
\hline & e. Very good & 35 & 28.92 \\
\hline & Total & 121 & 100 \\
\hline \multirow{6}{*}{ Relationship with own family } & a. Very Poor & - & - \\
\hline & b. Poor & 4 & 3.28 \\
\hline & c. Satisfactory & 15 & 12.30 \\
\hline & d. Good & 68 & 55.72 \\
\hline & e. Very good & 35 & 28.70 \\
\hline & Total & 122 & 100 \\
\hline \multirow{6}{*}{ Relationship with mother in-law } & a. Very Poor & - & - \\
\hline & b. Poor & 5 & 4.13 \\
\hline & c. Satisfactory & 17 & 14.05 \\
\hline & d. Good & 67 & 55.37 \\
\hline & e. Very good & 32 & 26.45 \\
\hline & Total & 121 & 100 \\
\hline
\end{tabular}




\begin{tabular}{|l|c|c|c|}
\hline \multirow{4}{*}{ Relationship with husband's family in general } & a. Very Poor & - & - \\
\cline { 2 - 4 } & b. Poor & 5 & 4.13 \\
\cline { 2 - 4 } & c. Satisfactory & 66 & 14.88 \\
\hline \multirow{nyyy}{*}{} & d. Good & 32 & 54.54 \\
\cline { 2 - 4 } & e. Very good & 121 & 26.45 \\
& Total & 100 \\
\hline
\end{tabular}

As the above Tables 2-6 show that $23.77 \%$ of respondent mothers were primigravida (being pregnant for the first time). $30.83 \%$ and $69.17 \%$ of respondent mothers were primipara (giving birth for the first time) and multipara (giving $\geq 2$ birth). $57.14 \%$ of the respondents had 1 miscarriage and stillbirths and the rest had $\geq 2$ miscarriage and stillbirths. $92.62 \%$ of respondent mothers had no any problems that faced the rest $7.38 \%$ had pregnancy related problems during their last pregnancy. Except 1 mother all the rest mothers gave birth in hospitals. $61.48 \%$ of the participating mothers delivered their babies by vaginal delivery, $38.52 \%$ delivered their babies by caesarean section, $2.46 \%$ reported the use of vacuum during delivery and $2.46 \%$ reported episiotomy was done during birth.27.87\% and $50.00 \%$ of mothers reported receiving very good and good medical care during birth. In contrast, $19.67 \%$ \& $2.46 \%$ reported that the medical care was Satisfactory and poor respectively.

Table 4: common PPD symptoms with respect to EPDS of the participants in Harar town, Hiwot Fana Specialized University Hospital from February 1-30, 2016

\begin{tabular}{|c|c|c|c|}
\hline Symptoms & & Frequency & $\%$ \\
\hline \multirow{5}{*}{$\begin{array}{l}\text { 1. I have been able to laugh and see the funny side of } \\
\text { things. }\end{array}$} & a. As much as I always could. & 110 & 90.16 \\
\hline & b. Not quite so much now. & 9 & 7.38 \\
\hline & c. Definitely not so much now. & 3 & 2.46 \\
\hline & d. Not at all. & - & - \\
\hline & Total & 122 & 100 \\
\hline \multirow{6}{*}{ 2.I have looked forward with enjoyment to things } & a. As much as I ever did. & 85 & 69.67 \\
\hline & b. Rather less than I used to. & 15 & 12.30 \\
\hline & c. Definitely less than I used to. & 8 & 6.56 \\
\hline & d. Hardly at all. & 14 & 11.47 \\
\hline & Total & & \\
\hline & 122 & 100 & \\
\hline \multirow{5}{*}{$\begin{array}{l}\text { 3. I have blamed myself unnecessarily when things } \\
\text { went wrong. }\end{array}$} & a. Yes, most of the time. & 5 & 4.10 \\
\hline & b. Yes, some of the time. & 39 & 31.97 \\
\hline & c. Not very often. & 41 & 33.61 \\
\hline & d. No, never. & 37 & 30.32 \\
\hline & Total & 122 & 100 \\
\hline \multirow{5}{*}{ 4.I have been anxious or worried for no good reason } & a. No not at all. & 50 & 40.98 \\
\hline & b. Hardly ever. & 34 & 27.87 \\
\hline & c. Yes, sometimes. & 26 & 21.31 \\
\hline & d. Yes, very often. & 12 & 9.84 \\
\hline & Total & 122 & 100 \\
\hline \multirow{5}{*}{$\begin{array}{l}\text { 5. I have felt scared or panicky for no very good } \\
\text { reason. }\end{array}$} & a. Yes, quite a lot. & 7 & 5.74 \\
\hline & b. Yes, sometimes. & 11 & 9.02 \\
\hline & c. No, Not much. & 30 & 24.59 \\
\hline & d. No, not at all. & 74 & 60.65 \\
\hline & Total & 122 & 100 \\
\hline \multirow{3}{*}{ 6. Things have been getting on top of me. } & a. Yes, most of the time I haven't been able to cope at all. & 3 & 2.46 \\
\hline & b. Yes, sometimes I haven't been coping as well as usual. & 13 & 10.65 \\
\hline & c. No, most of the time I have coped quite well. & 11 & 9.02 \\
\hline
\end{tabular}




\begin{tabular}{|c|c|c|c|}
\hline & d. No, I have been coping as well as ever. & 95 & 77.87 \\
\hline & Total & 122 & 100 \\
\hline \multirow{5}{*}{$\begin{array}{l}\text { 7. I have been so unhappy that I have had difficulty } \\
\text { sleeping. }\end{array}$} & a. Yes, most of the time. & 9 & 7.37 \\
\hline & b. Yes, sometimes. & 29 & 23.77 \\
\hline & c. Not very often. & 41 & 33.61 \\
\hline & d. No, not at all. & 43 & 35.25 \\
\hline & Total & 122 & 100 \\
\hline \multirow{5}{*}{ 8. I have felt sad or miserable. } & a. Yes, most of the time. & 9 & 7.38 \\
\hline & b. Yes, quite often. & 18 & 14.75 \\
\hline & c. Not very often. & 44 & 36.07 \\
\hline & d. No, not at all. & 51 & 41.80 \\
\hline & Total & 122 & 100 \\
\hline \multirow{5}{*}{ 9. I have been so unhappy that I have been crying. } & a. Yes, most of the time. & 7 & 5.74 \\
\hline & b. Yes, quite often. & 8 & 6.56 \\
\hline & c. Only occasionally. & 33 & 27.05 \\
\hline & d. No, never. & 74 & 60.65 \\
\hline & Total & 122 & 100 \\
\hline \multirow{5}{*}{$\begin{array}{l}\text { 10. The thought of harming myself has occurred to } \\
\text { me. }\end{array}$} & a. Yes, quite often. & 1 & 0.82 \\
\hline & b. Sometimes. & 9 & 7.38 \\
\hline & c. Hardly ever. & 3 & 2.46 \\
\hline & d. Never. & 109 & 89.34 \\
\hline & Total & 122 & 100 \\
\hline
\end{tabular}

Table 5: Association between PPD and Sociodemographic variables of the participants in Harar town, Hiwot Fana Specialized University Hospital from February 1-30, 2016

\begin{tabular}{|c|c|c|c|c|c|}
\hline Variables & Categories & depressed & Not depressed & Total & OR \\
\hline \multirow{6}{*}{ 1.age } & a. $15-19$ & $0(0 \%)$ & $6(100 \%)$ & 6 & 0 \\
\hline & b. $20-24$ & $6(10.34 \%)$ & $52(89.66 \%)$ & 58 & 0.25 \\
\hline & c. $25-29$ & $4(11.43 \%)$ & $31(88.57 \%)$ & 35 & 0.28 \\
\hline & d. $30-34$ & $5(31.25 \%)$ & $11(68.75 \%)$ & 16 & 1 \\
\hline & E.35-39 & $1(20 \%)$ & $4(80 \%)$ & 5 & 0.55 \\
\hline & $\geq 40$ & $0(0 \%)$ & $2(100 \%)$ & 2 & 0 \\
\hline \multirow{5}{*}{ 2. Religion } & a. Orthodox & $1(4.17 \%)$ & $23(95.83 \%)$ & 24 & 0.09 \\
\hline & b. protestant & & & & \\
\hline & $2(33.33 \%)$ & $4(66.67 \%)$ & 6 & 1 & \\
\hline & c. Muslim & $13(14.13 \%)$ & $79(85.87 \%)$ & 92 & 0.33 \\
\hline & d. others & 0 & 0 & 0 & -- \\
\hline \multirow{4}{*}{ 3. Ethnicity } & a. Amhara & $1(6.25 \%)$ & $15(93.75 \%)$ & 16 & 0.37 \\
\hline & b. Oromo & $12(15.19 \%)$ & $67(84.81 \%)$ & 79 & 1 \\
\hline & c. Harari & $1(7.69 \%)$ & $12(92.31)$ & 13 & 0.47 \\
\hline & d. Others & $2(14.29 \%)$ & $12(85.71 \%)$ & 14 & 0.93 \\
\hline \multirow{5}{*}{ 3.Marital status } & a. married & $15(12.40 \%)$ & $106(87.60 \%)$ & 121 & 0 \\
\hline & b.single & $1(100 \%)$ & 0 & 1 & 1 \\
\hline & c. divorced & 0 & 0 & 0 & - \\
\hline & d. widowed & 0 & 0 & 0 & - \\
\hline & e. others & 0 & 0 & 0 & - \\
\hline 4.Residence: & a. urban & $8(11.6 \%)$ & 61(88.4\%) & 69 & 0.74 \\
\hline
\end{tabular}




\begin{tabular}{|c|c|c|c|c|c|}
\hline & b. rural & $8(15.1 \%)$ & $45(84.9 \%)$ & 53 & 1.35 \\
\hline \multirow{5}{*}{$\begin{array}{l}\text { 6.Educational } \\
\text { status: }\end{array}$} & a. unable to read and write & $8(12.90 \%)$ & $54(87.10 \%)$ & 62 & 0.59 \\
\hline & b. only reading and writing & 0 & 0 & 0 & - \\
\hline & c. Elementary school & $3(11.11 \%)$ & $24(88.89 \%)$ & 27 & 0.5 \\
\hline & $\begin{array}{l}\text { d. High school and } \\
\text { preparatory }\end{array}$ & $4(20 \%)$ & $16(60 \%)$ & 20 & 1 \\
\hline & e. College graduate & $1(7.70 \%)$ & $12(92.30 \%)$ & 13 & 0.33 \\
\hline \multirow{7}{*}{ 7.0ccupation: } & a. Housewife & $10(15.87 \%)$ & $53(84.13 \%)$ & 63 & - \\
\hline & b. Government employed & $0(0 \%)$ & $10(100 \%)$ & 10 & 0 \\
\hline & c. self Employed & $0(0 \%)$ & $2(100 \%)$ & 2 & 0 \\
\hline & d. Farmer & $2(6.45 \%)$ & $29(93.55 \%)$ & 31 & 0 \\
\hline & e. Student & $1(100 \%)$ & 0 & 1 & 1 \\
\hline & f. Merchant & $3(20 \%)$ & $12(80 \%)$ & 15 & 0 \\
\hline & g. Others (please state__) & 0 & 0 & 0 & - \\
\hline \multirow{3}{*}{$\begin{array}{l}\text { 8.Family monthly } \\
\text { income: }\end{array}$} & $<750$ & $14(21.54 \%)$ & $51(78.46 \%)$ & 65 & 1 \\
\hline & $750-1200$ & $1(2.27 \%)$ & $43(97.73 \%)$ & 44 & 0.08 \\
\hline & $\geq 1200$ & $1(7.69 \%)$ & $12(92.31 \%)$ & 13 & 0.30 \\
\hline
\end{tabular}

Table 6: Association between PPD and Pregnancy and Birth variables of the participants in Harar town, Hiwot Fana Specialized University Hospital from February 1-30, 2016

\begin{tabular}{|c|c|c|c|c|c|}
\hline Variable & Categories & Depressed & Not depressed & Total & OR \\
\hline \multirow{2}{*}{ Number of pregnancy } & a. 1 & $5(17.24 \%)$ & $24(82.76 \%)$ & 29 & 1.55 \\
\hline & b. $>2$ & $11(11.83 \%)$ & $82(88.17 \%)$ & 93 & 0.64 \\
\hline \multirow{2}{*}{ Number of births } & a. 1 & $5(13.51 \%)$ & $32(86.49 \%)$ & 37 & 1.14 \\
\hline & b. $>2$ & $10(12.05 \%)$ & 73(87.95\%) & 83 & 0.87 \\
\hline \multirow{2}{*}{ Number of abortion } & a. 1 & $5(15 \%)$ & $15(75 \%)$ & 20 & 4.67 \\
\hline & b. $>2$ & $1(6.67 \%)$ & $14(93.33 \%)$ & 15 & 0.21 \\
\hline \multirow{2}{*}{$\begin{array}{l}\text { Number of live } \\
\text { children }\end{array}$} & a. 1 & $4(11.43 \%)$ & $31(88.57 \%)$ & 35 & 0.94 \\
\hline & b. $>2$ & $10(12.05 \%)$ & 73(87.95\%) & 83 & 1.06 \\
\hline \multirow{3}{*}{ Place of birth } & a. Health institution & $15(12.40 \%)$ & $106(87.60 \%)$ & 121 & 0 \\
\hline & b. Home & $1(100 \%)$ & 0 & 1 & - \\
\hline & c. Others & 0 & 0 & & \\
\hline \multirow{2}{*}{ Route of last delivery } & a. Vaginal delivery & $7(9.33 \%)$ & $68(90.66 \%)$ & 75 & 0.43 \\
\hline & b. Caesarean section & $9(19.15 \%)$ & $38(80.85 \%)$ & 47 & 2.3 \\
\hline \multirow{2}{*}{ Use of vacuum } & a. yes & 0 & $3(100 \%)$ & 3 & 0 \\
\hline & b. no & $16(13.44 \%)$ & 103(86.56\%) & 119 & - \\
\hline \multirow{2}{*}{ Episiotomy } & a. yes & $1(33.33 \%)$ & $2(66.67 \%)$ & 3 & 3.47 \\
\hline & b. no & $15(14.42 \%)$ & $104(85.58 \%)$ & 119 & 0.28 \\
\hline \multirow{2}{*}{$\begin{array}{l}\text { Desired to the last } \\
\text { pregnancy }\end{array}$} & a. yes & $14(11.76 \%)$ & 105(88.24\%) & 119 & 0.07 \\
\hline & b. no & $2(66.67 \%)$ & $1(33.33 \%)$ & 3 & 15 \\
\hline \multirow{2}{*}{$\begin{array}{l}\text { plan with husband } \\
\text { to have the last } \\
\text { pregnancy }\end{array}$} & a. yes & $14(11.76 \%)$ & 105(88.24\%) & 119 & 0.07 \\
\hline & b. no & $2(66.67 \%)$ & $1(33.33 \%)$ & 3 & 15 \\
\hline \multirow{2}{*}{$\begin{array}{l}\text { Medical care during } \\
\text { birth }\end{array}$} & a. Poor & $10(37.04 \%)$ & $17(62.96 \%)$ & 27 & 8.73 \\
\hline & b. Good & $6(6.32 \%)$ & $89(93.68 \%)$ & 95 & 0.11 \\
\hline
\end{tabular}




\section{Section three: New born related factors: (these questions are related to your last baby)}

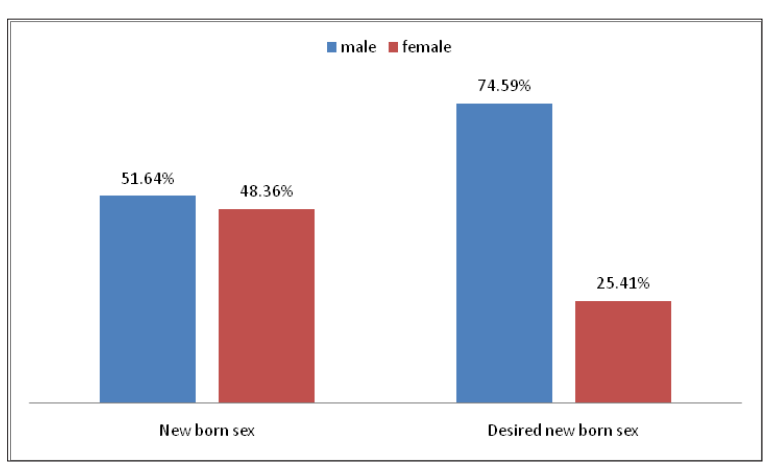

Figure 3: New born related factors of the participants in Harar town, Hiwot Fana Specialized University Hospital from February 1-30, 2016.

$63(51.64 \%)$ of the participating mothers gave birth to a male baby and 59(48.36\%) gave birth to a female. When the mothers were asked about the preferred or desired sex of the baby, 91(74.59\%) chose a male, 31(25.24\%) chose a female (Figures 3 \& 4). $16(13.15 \%)$ of mothers reported that their baby was ill, but $106(86.85 \%)$ of mothers reported that their baby was free from illness. $10(8.20 \%)$ of mothers reported that their baby admitted neonate intensive care unit soon after birth, but for the rest. $7(5.76 \%)$ of the mothers reported that their baby was premature or delivered before completing 9 months of pregnancy and the rest mothers reported that their baby was full term.117(95.90\%) of the mothers reported that breast feeding is the sole feeding type and $5(4.10 \%)$ reported using formula feeding exclusively.

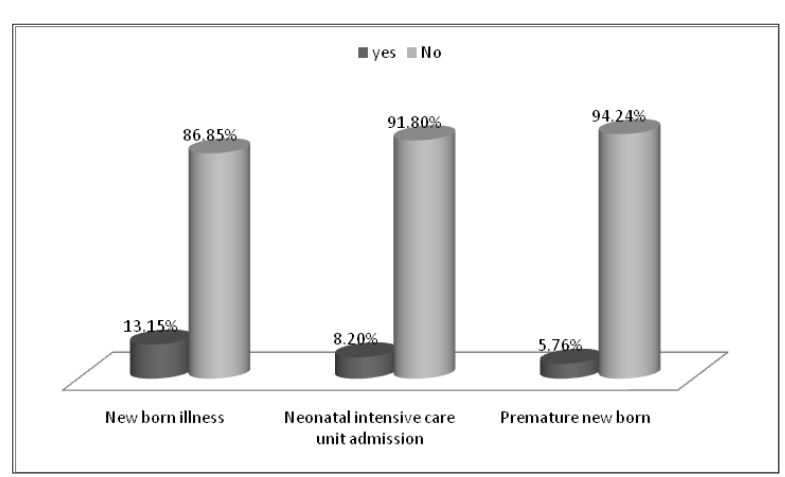

Figure 4: New born related factors of the participants in Harar town, Hiwot Fana Specialized University Hospital from February 1-30, 2016.

\section{Section four: Marital and Family Relationship Factors}

The participating mothers were asked five questions regarding their satisfaction and evaluation of their relationship with their husband, their own families, their mother's in-laws and their husband families in general. About $0.83 \%$ of respondents had very poor relationships, $1.65 \%$ had poor relationships, $14.87 \%$ had satisfactory relationships, $53.73 \%$ had good relationships and $28.92 \%$ had very good relationships with their husband.0.82\% of respondents got very poor, $4.96 \%$ got poor, $13.22 \%$ got satisfactory,
$52.07 \%$ got good and $28.92 \%$ got very good help and support from their husband.3.28\%, $12.30 \%, 55.72 \%$ and $28.70 \%$ of respondents had poor, satisfactory, good and very good relationships with their own family respectively. About 4.13\%, 14.05\%, 55.37\% and $26.45 \%$ of the respondents had poor, satisfactory, good and very good relationships with their mother's in-law respectively. $4.13 \%$ of respondents had poor, $14.88 \%$ had satisfactory, $54.54 \%$ had good and $26.45 \%$ had very good relationship with their husband family in general.

\section{Section five: psychosocial and psychological history}

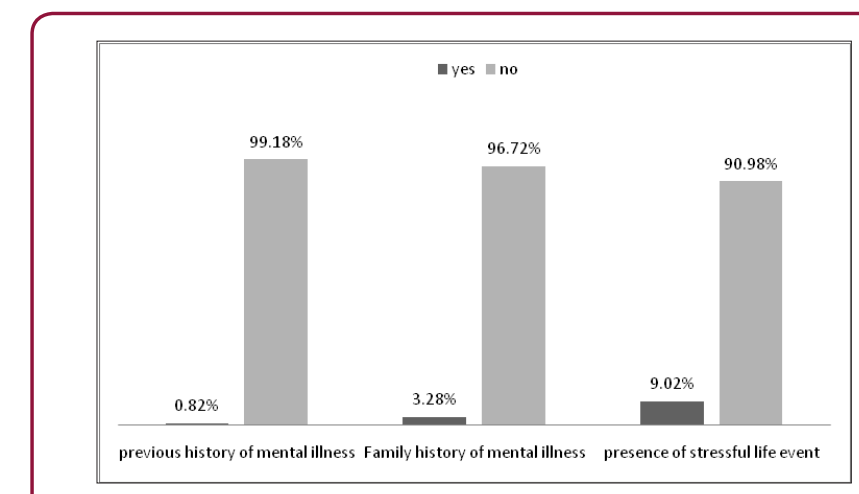

Figure 5: psychosocial and psychological characteristics of the participants in Harar town, Hiwot Fana Specialized University Hospital from February 1-30, 2016.

Figure 5, Only $1(0.82 \%)$ reported having personal mental history and $4(3.28 \%)$ having family mental history. The participating mothers were asked about 11 psychosocial stressors and if they had experienced any of them during their pregnancy. Among them 11(9.02\%) had experienced at least one stressful life event. The most reported stressor was death of a dear person affecting $6(33.33 \%)$ of mothers, followed by recurrent verbal abuse $3(16.67 \%)$, financial problems $3(16.67 \%)$, accidents or injuries $2(11.11 \%)$, physical abuse $2(11.11 \%)$, abandon a dear person $1(5.56 \%)$ and housing problems $1(5.56 \%)$ and the rest stressors such as work place problems, separation or divorce, severe illness of you or dear person and difficulty in dealing with your children accounts zero percent (0\%)(Figure 6).

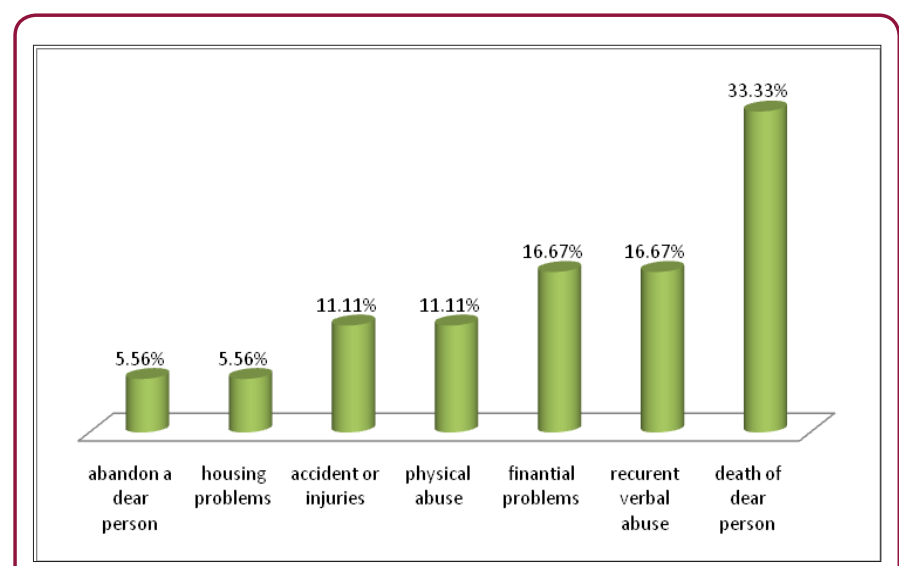

Figure 6: prevalence of stressful life events during pregnancy in Harar town, Hiwot Fana Specialized University Hospital from February 1-30, 2016. 


\section{Section six: Edinburgh Depression Scale}

From Table 4.

\section{Prevalence of postpartum depression}

According to this result, out of the 122 mothers participated, $16(13.11 \%)$ were found to have postpartum depressive symptoms as measured by an EPDS score of $\geq 13$. Potential risk factors for
PDD were shown below by Tables 7-11. Undesired and unplanned pregnancy, poor satisfaction with medical care, premature new born, poor support provided by husband, poor relationship with husband family, recurrent verbal abuse, and family history of mental illness had strong association with PPD. 16 out of 122 study participants screened positive for postpartum depression as tabulated from a score $\geq 13$ on the EPDS (Figure 7).

Table 7: Association between PPD and Pregnancy and Birth related stressors of the participants in Harar town, Hiwot Fana Specialized University Hospital from February 1-30, 2016.

\begin{tabular}{|c|c|c|c|c|c|}
\hline Variables & Categories & Depressed & Not depressed & Total & OR \\
\hline \multirow[t]{2}{*}{ Hypertension } & Yes & $1(50 \%)$ & $1(50 \%)$ & 2 & 7 \\
\hline & No & $15(12.5 \%)$ & 105(87.5\%) & 120 & 0.14 \\
\hline \multirow[t]{2}{*}{ Epilepsy } & Yes & $1(100 \%)$ & 0 & 1 & - \\
\hline & No & $15(12.40 \%)$ & $106(87.6 \%)$ & 121 & 0 \\
\hline \multirow[t]{2}{*}{ Hyper emesis } & Yes & $3(42.86 \%)$ & $4(57.14 \%)$ & 7 & 5.30 \\
\hline & No & $13(12.38 \%)$ & $92(87.62 \%)$ & 105 & 0.18 \\
\hline \multirow[t]{2}{*}{$\begin{array}{l}\text { Generalized body } \\
\text { swelling }\end{array}$} & Yes & $1(100 \%)$ & 0 & 1 & - \\
\hline & No & $15(12.40 \%)$ & $106(87.60 \%)$ & 121 & 0 \\
\hline \multirow[t]{2}{*}{ Anemia } & Yes & $1(100 \%)$ & 0 & 1 & - \\
\hline & No & $15(12.40 \%)$ & $106(87.60 \%)$ & 121 & 0 \\
\hline
\end{tabular}

Table 8: Association between PPD and new born related factors of the participants in Harar town, Hiwot Fana Specialized University Hospital from February 1-30, 2016

\begin{tabular}{|c|c|c|c|c|c|}
\hline Variables & Categories & Depressed & Not depressed & Total & OR \\
\hline \multirow{2}{*}{ New born sex } & a. Male & 8 & 55 & 63 & 0.93 \\
\hline & b. female & 8 & 51 & 59 & 1.07 \\
\hline \multirow[t]{2}{*}{ Desired new born sex } & a. Male & 15 & 76 & 91 & 6.20 \\
\hline & b.female & 1 & 30 & 31 & 0.16 \\
\hline \multirow[t]{2}{*}{ New born illness } & Yes & 4 & 12 & 16 & 2.6 \\
\hline & No & 12 & 94 & 106 & 0.38 \\
\hline \multirow{2}{*}{$\begin{array}{l}\text { Neonatal intensive } \\
\text { care unit admission }\end{array}$} & a. yes & 3 & 7 & 10 & 3.3 \\
\hline & b. no & 13 & 99 & 112 & 0.30 \\
\hline \multirow{2}{*}{ Premature newborn } & a. yes & 4 & 3 & 7 & 11.4 \\
\hline & b. no & 12 & 103 & 115 & 0.09 \\
\hline \multirow{2}{*}{ Feeding type } & a. breast feeding & 15 & 102 & 117 & 0.6 \\
\hline & b. formula feeding & 1 & 4 & 5 & 1.7 \\
\hline
\end{tabular}

Table 9: Association between PPD and social support and family Relationship variables of the participants in Harar town, Hiwot Fana Specialized University Hospital from February 1-30, 2016

\begin{tabular}{|c|c|c|c|c|c|}
\hline Variable & Categories & Depressed & Not depressed & Total & OR \\
\hline \multirow{2}{*}{$\begin{array}{c}\text { 1. Relationship with } \\
\text { husband }\end{array}$} & a. Poor & 8 & 13 & 21 & 7.1 \\
\cline { 2 - 6 } & b. good & 8 & 92 & 23 & 0.14 \\
\hline \multirow{2}{*}{$\begin{array}{c}\text { 2. Help and support } \\
\text { provided by husband }\end{array}$} & a. Poor & 9 & 14 & 98 & 0.4 \\
\hline \multirow{2}{*}{$\begin{array}{c}\text { 3. Relationship with } \\
\text { own family }\end{array}$} & b. good & 7 & 91 & 19 & 3.0 \\
\hline \multirow{2}{*}{$\begin{array}{c}\text { 4. Relationship with } \\
\text { mother in-law }\end{array}$} & b. Poor & 5 & 92 & 103 & 0.33 \\
\cline { 2 - 6 } & b. Poor & 8 & 11 & 22 & 6.5 \\
\hline
\end{tabular}




\begin{tabular}{|c|c|c|c|c|c|}
\hline \multirow{2}{*}{$\begin{array}{c}\text { 5. Relationship with } \\
\text { husband's family in } \\
\text { general }\end{array}$} & a. Poor & 9 & & & \\
\cline { 2 - 6 } & 14 & 23 & 8.4 & & \\
\cline { 2 - 6 } & b. good & 7 & 91 & 98 & 0.12 \\
\hline
\end{tabular}

Table 10: Association between PPD and mental and psychological variables of the participants in Harar town, Hiwot Fana Specialized University Hospital from February 1-30, 2016.

\begin{tabular}{|c|c|c|c|c|c|}
\hline Variables & Categories & Depressed & Not depressed & Total & OR \\
\hline Personal mental Hx & Yes & 1 & 0 & 1 & 0 \\
\hline & No & 15 & 106 & 4 & 7.42 \\
\hline Family mental Hx & Yes & 2 & 104 & 118 & 0.13 \\
\hline
\end{tabular}

Table 11: 1. shown below seven of the tested 11 stressful life events during pregnancy was significantly associated with the presence of PPD. These were: abandon a dear person $1(100 \%)$ has PPD compared to $12.40 \%$ of not reporting this event), recurrent verbal abuse (66.7\% had PPD compared to $11.76 \%$ of not reporting this event and it had odds of 15 ), accidents or injuries (50\% had PPD compared to $12.50 \%$ of not reporting this event and it had odds of 7 ) and death of a dear person (50\% had PPD compared to $11.21 \%$ of not reporting this event and it had odds of 7.92).

2. Association between PPD and mental and psychological variables (stressful life events) of the participants in Harar town, Hiwot Fana Specialized University Hospital from February 1-30, 2016.

\begin{tabular}{|c|c|c|c|c|c|}
\hline Variables & & depressed & Not depressed & Total & OR \\
\hline \multirow{2}{*}{$\begin{array}{l}\text { A) Abandon a dear } \\
\text { person }\end{array}$} & Yes & 1 & 0 & 1 & $\underline{-}$ \\
\hline & No & 15 & 107 & 121 & 0 \\
\hline \multirow{2}{*}{$\begin{array}{l}\text { B) Recurrent verbal } \\
\text { abuse }\end{array}$} & Yes & 2 & 1 & 3 & 15 \\
\hline & No & 14 & 105 & 119 & 0.06 \\
\hline \multirow{2}{*}{$\begin{array}{l}\text { C) Housing problem } \\
\text { or change }\end{array}$} & Yes & 1 & 0 & 1 & $\underline{-}$ \\
\hline & No & 15 & 106 & 121 & 0 \\
\hline \multirow{2}{*}{ D) Physical abuse } & Yes & 2 & 0 & 2 & 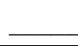 \\
\hline & No & 14 & 106 & 120 & 0 \\
\hline \multirow{2}{*}{ E) Financial problems } & Yes & 3 & 0 & 3 & 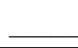 \\
\hline & No & 13 & 106 & 119 & 0 \\
\hline \multirow{2}{*}{$\begin{array}{l}\text { F) Accidents or } \\
\text { injuries }\end{array}$} & Yes & 1 & 1 & 2 & 7 \\
\hline & No & 15 & 105 & 120 & 0.14 \\
\hline \multirow{2}{*}{$\begin{array}{l}\text { G) Death of a dear } \\
\text { person }\end{array}$} & Yes & 3 & 3 & 6 & 7.92 \\
\hline & No & 13 & 103 & 116 & 0.12 \\
\hline
\end{tabular}

\section{percentage $\%$}

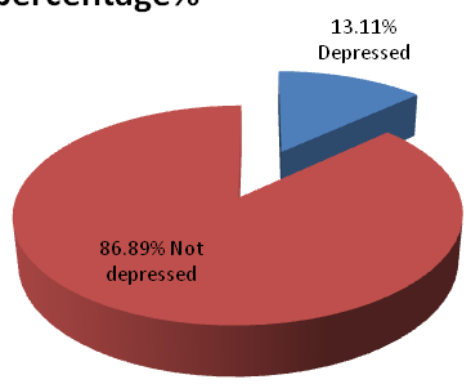

Figure 7: Prevalence of PPD among mothers attending at Hiwot Fana Specialized University Hospital from February 1-30, 2016.

\section{Factors associated with PPD}

a. Socio Demographic Characteristics

Among the total participants those who were from rural had
1.35 odds than urban women. Factors such as age, religion, ethnicity, occupation, marital status, educational status, and income had no significant association with PPD according to this finding. From above table primigravida had odds of 1.55 than multigravida and prim parity had odds of 1.14 than those with milt parity. High Odds ratio of PPD were associated with; mothers who had abortion for the first time 4.67, Caesarean section delivery 2, episiotomy during their delivery 3.47 , Unplanned pregnancy 15 , and poor satisfaction by medical care 9 . Among the pregnancy related problems as shown below by Table 7 , high odds ratio of PPD were associated with hyper emesis 5 and hypertension 7. The rest of problems had no significant association with the disorder. Under new born related factors high odds of PPD were associated with desired male sex 6, mothers who have premature newborn 11 and mothers who had baby with health problem 2.6. The other factors had no significant association with PPD [1-14].

As the table below show, the association between family relationship and PPD was tested.PPD (EPDS cut off $\geq 13$ ) was 
significantly associated with poor husband and marital relationship satisfaction with PPD rate of $38.1 \%$ and $8 \%$ among mothers reporting poor and good relationship respectively (OR=7.1), poor husband help and support with PPD 39.13\% and 7.70\% among mothers reporting poor and good support and help respectively $(O R=8.4)$ and poor mother in-law relationship satisfaction with PPD rate of $36.36 \%$ and $8 \%$ among mothers reporting poor and good relationship respectively $(\mathrm{OR}=6.5)$. Poor relationships with husband's family in general had odds of 8.4. As table shown below one of mother reported a personal history of mental illness and she had PPD. Family history of mental illness had odds of 7.42. In general high odds of PPD were associated with undesired and unplanned pregnancy, poor satisfaction with medical care, hypertension and hyper emesis, desired new born sex (male), admission of newborn to ICU, premature new born, poor relationship with husband, husband families, mother-in-law, poor support from husband, family history of mental illness, recurrent verbal abuse, accident and death of dear person.

\section{Discussion}

\section{Prevalence and its Associated Factors}

The aim of this study is to determine the prevalence of PPD and its associated factors of mothers who attained at HFSUH. There are also another studies conducted on this topic which done in the different part of the world. Research conducted in Brazil by using cohort study, a total of 1,340 pregnant women were identified. The prevalence of postpartum depression was $16.5 \%$. The adjusted analysis found the risk factors for PPD to include lower socioeconomic status, not living with a partner, previous stressful events [11]. While this study shows the prevalence of PPD was $13.11 \%$. The associated factors that strongly linked with PPD were unplanned pregnancy, premature baby, poor support systems, poor satisfaction with medical care, and family history of mental illness, recurrent verbal abuse, accident and death of loved one.

The other factors such as cesarean section, episiotomy, neonate illness, desired new born sex, hypertension, and hyper emesis had also their own significant association. This discrepancy may be due to methodological differences such as: study design (cohort study design used while in this study used cross-sectional study design), the number of women's who participate in the study, cultural variation in terms of social support and the timing at which the study was done after delivery. According to research done in France, from the sample of 2393 mothers, the rates of PPD were $40 \%$ high at early postpartum period among women with premature infants. Sustained depression was associated with earlier gestational age, lower birth weight, ongoing infant illness/disability and perceived lack of social support [12]. While this study shows the prevalence of PPD was $13.11 \%$. The associated factors that strongly linked with PPD were unplanned pregnancy, premature baby, poor support systems, poor satisfaction with medical care, and family history of mental illness, recurrent verbal abuse, accident and death of loved one. The other factors such as cesarean section, episiotomy, neonate illness, desired new born sex, hypertension, and hyper emesis had also their own significant association. The possible reason for this variation might be the difference in sample size, and regional/ culture of society. In addition to this, the research done in France was specific to women with premature baby.

Research conducted in Iran by using cross-section study out of 6,627 women in their postpartum period were identified and screened for possible depression using BDI. Of these, 57.1\% were screened possible cases of depression and based on BDI scores, $20 \%$ (1324) fell within the mild range of scores, 18.3\% (1211) within the moderate range, and $18.9 \%$ (1251) within the severe range. Previous history of an affective disorder, history of depression is consistently a strong risk factor for PPD. The research also found a $35.8 \%$ prevalence rate of severe depression (based on BDI score) in women with a past history of depression [13]. But in this study the prevalence of PPD was $13.11 \%$. The associated factors that strongly linked with PPD were unplanned pregnancy, premature baby, poor support systems, poor satisfaction with medical care, and family history of mental illness, recurrent verbal abuse, accident and death of loved one.

The other factors such as cesarean section, episiotomy, neonate illness, desired new born sex, hypertension, and hyper emesis had also their own significant association. This great difference is may be due to sample size, screening instrument and geographical location/living circumstance of society might be contributed. Out of the 149 Pakistani women assessed at 12 weeks in the postnatal period, using the Edinburgh Postnatal Depression Scale (EPDS), Multidimensional Scale of Perceived Social Support (MSPSS) and Personal Information Questionnaire (PIQ),53 scored 12 or above on the EPDS, giving an estimated prevalence of postnatal depression of $36 \%$. Sixty-six percent of the women screening positive in the postnatal period had significant levels of Psychological distress in the antenatal period [14]. In this study the prevalence of PPD was $13.11 \%$.

The associated factors that strongly linked with PPD were unplanned pregnancy, premature baby, poor support systems, poor satisfaction with medical care, and family history of mental illness, recurrent verbal abuse, accident and death of loved one. The other factors such as cesarean section, episiotomy, neonate illness, desired new born sex, hypertension, and hyper emesis had also their own significant association. The variation when compared might be due to timing at which the study was done three months after delivery, multiple screening instrument use, and slight difference in sample size. On the other hand, when we compare this result with similar studies done in Africa which found the prevalence of PPD at Kenya was $10.6 \%$ and its associated factors were being unemployment and low household income, were significantly associated with PPD. High Odds ratio of PPD were associated with; sex of infant not desired, being on medication, pregnancy not wanted, prim parity, and been single.

Factors such as age, C/section as mode of delivery were insignificantly associated with PPD [6]. While this study shows the prevalence of PPD was $13.11 \%$. The associated factors that strongly linked with PPD were unplanned pregnancy, premature baby, poor support systems, poor satisfaction with medical care, and family 
history of mental illness, recurrent verbal abuse, accident and death of loved one. The other factors such as cesarean section, episiotomy, neonate illness, desired new born sex, hypertension, and hyper emesis had also their own significant association. The reasons for this slight difference may be timing at which the study was done three months after delivery, the cultural variation and slight variation in their sample size. The fact that the literature demonstrates a wide variations in what is considered as a significant score on the EPDS, may be the prevalence would have been higher had the significant score been lowered to 11 or 12 as described in the development of the EPDS. Further the prevalence obtained in this study could be an underestimate since some mothers may not have attended post natal care especially if they felt like they were physically well, if they are uneducated or of low socio economic status.

\section{Limitation}

Hospital based population may have placed a highly selective group of respondents as seen in the high number of mothers delivered via cesarean section (38.52\%) and women's who have post natal complication. This could have been due to mothers delivered via cesarean section and women are who have post natal complication coming for postnatal care at HFSUH. Most of post natal mothers attained care up to 2 weeks after delivery, so post natal mothers after this period of time didn't present at study area. There might be mothers who are not available during data collection this decrease the number of cases.

\section{Conclusion}

This study found a prevalence of PPD among women delivering at HFSUH, one week after delivery was $13.11 \%$ which is a significant high value and compared well with other studies. The associated factors that strongly linked with PPD were unplanned pregnancy, premature baby, poor support systems, poor satisfaction with medical care, and family history of mental illness, recurrent verbal abuse, accident and death of loved one. The other factors such as cesarean section, episiotomy, neonate illness, desired new born sex, hypertension, and hyper emesis had also their own significant association. Residence, educational status, number of birth, age, place of delivery and sex of new born had no significant association with PPD. The findings in this study may form the bases for the need of routine screening of PPD in the post natal care especially those mothers with unplanned pregnancy, premature baby, poor support systems, poor satisfaction with medical care, family history of mental illness, recurrent verbal abuse, accident and death of loved one. This would help prevent PPD at all levels hence a healthy mother.

\section{Recommendations}

We would like to recommend

a) Psychiatry staff of Hiwot Fana Specialized University Hospital should collaborates the services given for psychiatric cases and other gynecologic and obstetrics as well as general medical conditions. b) The result should be available for the Hiwot Fana staff to alert them on magnitude of PPD.

c) Hiwot Fana staff should be routinely screen for mental illness just like other reproductive health problems for mothers attending hospital during delivery and after delivery.

d) Researchers should have do further researches by different study design, at other health institutions.

e) Haramaya University College of health and medical science, Hiwot Fana Specialized University Hospital should plan common policy to intervene the identified problem.

f) Finally ministry of health should design policies that interactively provide service on mental illness of mother and their reproductive problems.

\section{References}

1. Benjamin J Sadock, Virginia A Sadock, Pedro Ruiz MD (2016) Kaplan and Sadock's Synopsis of Psychiatry. Behavioral Sciences/Clinical Psychiatry. Tijdschrift voor Psychiatrie 58(1): 78-79.

2. Shahverdi H, Sohrabi M (2012) Three-phase relative permeability and hystresis model for simulation of water alternating gas (WAG) injection. SPE Improved Oil Recovery Symposium Society of Petroleum Engineers.

3. Syros V Galenic (2013) Medicine and Social Stability in Early Modern Florence and the Islamic Empires. Journal of Early Modern History 17(2): 161-213.

4. Thurgood S, Avery DM, Williamson L (2009) Postpartum depression (PPD). American Journal of Clinical Medicine 6(2): 17-22.

5. Cloonan N, Forrest AR, Kolle G, Gardiner BB, Faulkner GJ, et al. (2008) Stem cell transcriptome profiling via massive-scale mRNA sequencing. Nature methods 5(7): 613-619.

6. UoN VMMM. Prevalence of postpartum depression among women delivering at Kenyatta national hospital. 2012.

7. Cox JJ, Reimann F, Nicholas AK, Thornton G, Roberts E, et al. (2006) An SCN9A channelopathy causes congenital inability to experience pain. Nature 444(7121): 894-898.

8. Crimins JL, Pooler A, Polydoro M, Luebke JI, Spires-Jones TL, et al. (2013) The intersection of amyloid beta and tau in glutamatergic synaptic dysfunction and collapse in Alzheimer's disease. Ageing research reviews 12(3): 757-63.

9. Motuma A (2012) Youth-friendly health services utilization and factors in Harar, Ethiopia. Harar Bulletin of Health Sciences 4:15-21.

10. Getachew T, Tadiwos Y, Sisay M (2016) Evaluation of the prescribing practice using WHO core prescribing indicators in Hiwot Fana Specialized University Hospital, Harar, eastern Ethiopia. Journal of Drug Delivery and Therapeutics 6(6): 25-30.

11. Silva R, Jansen K, Souza L, Quevedo L, Barbosa L, et al. (2012) Sociodemographic risk factors of perinatal depression: a cohort study in the public health care system. Revista Brasileira de Psiquiatria 34(2): 143-148.

12. Baert S, De Raedt R, SchachtR, Koster EH (2010) Attentional bias training in depression: therapeutic effects depend on depression severity. Journal of behavior therapy and experimental psychiatry 41(3): 265-274.

13. Kheirabadi G R, Maracy M R, Barekatain M, Casey PR, Salehi M, et al. (2009) Risk factors of postpartum depression in rural areas of Isfahan Province, Iran.

14. Husain N, Bevc I, Husain M, Chaudhry I, Atif N, Rahman A, et al. (2006) Prevalence and social correlates of postnatal depression in a low income country. Archives of women's mental health 9(4): 197-202. 
(c) (i) This work is licensed under Creative

Submission Link: Submit Article

DOI: $10.32474 /$ OAJRSD.2018.01.000102

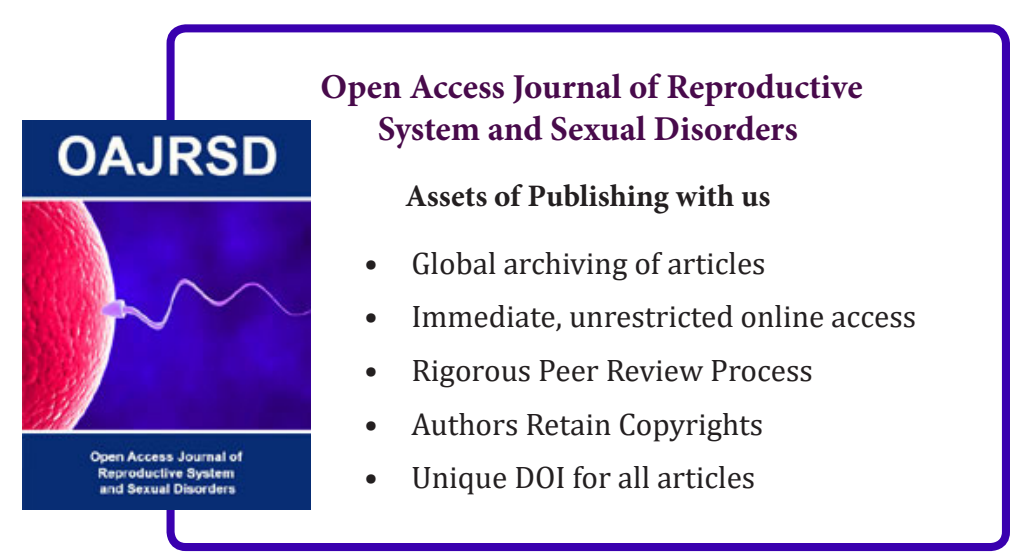

